\title{
The Actual Purchase of Herbal Products in Malaysia: The Moderating Effect of Perceived Benefit
}

\author{
Sarina Ismail ${ }^{\mathrm{a} *}$, Sany Sanuri Mohd Mokhtar ${ }^{\mathrm{a}}$ \\ * Corresponding author: Sarina Ismail, isarina4@gmail.com \\ ${ }^{a}$ School of Bussiness Management, Universiti Utara Malaysia, isarina4@gmail.com
}

\begin{abstract}
http://dx.doi.org/10.15405/epsbs.2016.08.13

Due to the increase interest in herbal products, the global herbal industry has expanded tremendously. There are several factors that have contributed to this situation, most important of which is changes in lifestyle. Even though there are indicators showing increase in demand of herbal products, there is a paucity of studies examining actual purchase. Hence the main objective of the study is to investigate the factors that influence the actual purchase of herbal products based on the theory of planned behaviour (TPB). This study has enhanced the understanding the factors that influence the actual purchase of herbal products. Nevertheless, the findings will be useful to entrepreneurs who are interested in knowing the fundamental factors that influence actual purchase of herbal products.
\end{abstract}

C 2016 Published by Future Academy www.FutureAcademy.org.uk

Keywords: Actual Purchase; Herbal Product; Perceived Benefit; Malaysia

\section{Introductions}

The increase of the worldwide demand of the natural product such as herbal are basically due to the awareness of healthy lifestyle (Ab Karim, Nasouddin, Othman, Mohd Adzahan, \& Hussin, 2011). Due to the increased interest, the world market value of the herbal industry has gradually increased from 2010-2015 with the annual return from USD29.5 to USD35.7 million. Meanwhile the sales of herbal product in United State have reached USD4.6 million, Eastern Europe, USD1.2 million and Asia Pacific, USD21.1 million (Euromonitor International, 2016). Previous studies also encounter a few reasons that relate to the situation. For example, change in lifestyle which is as a result of modernization processes and health problems (Saokaew, Suwankesawong, Permsuwan, \&

\section{(i) $\odot$}

EY NC No This is an Open Access article distributed under the terms of the Creative Commons Attribution-Noncommercial 4.0 Unported License, permitting all non-commercial use, distribution, and reproduction in any medium, provided the original work is properly cited. 
eISSN: 2357-1330

Selection and peer-review under responsibility of the Organizing Committee

Chaiyakunapruk, 2011). Past studies have proven that individuals who care about their health will strive to maintain a healthy life by using products that can be benefit to their overall health and general well-being (Kim \& Chung, 2011). Although there was an increase in demand for herbal products, there is a paucity of empirical endeavors actually looking at actual buying with specific focus on knowledge, customer retention and purchase intention (Rezai, Zahran, \& Mohamed, 2013). According to Aziz \& Tey (2009) there has been little research focusing on actual purchase in the contact of marketing hence the study on how and why consumers respond to actual purchase is still lacking. The main objective of this study is to investigate the factors that influence the actual purchase of herbal products based on the theory of planned behaviour (TPB) by Ajzen (1985).

\section{Literature Review}

\subsection{Actual Purchase}

The knowledge on actual purchase is consider important and enable the researchers in understanding customers' needs and also identify the marketing strategy and to ensure the continuity of the business (Paul \& Rana, 2012). According Ajzen (1985) actual purchase is customer's keenness to purchase product or service. Other studies related to actual behaviour have use predictors such as: intention (Al-Ekam, 2013) and perceived behaviour control (Zia-ur-Rehman \& Dost, 2013), subjective norm (Pomsanam, Napompech, \& Suwanmaneepong, 2014). Meanwhile study by Shafiq, Raza, \& Ziaur-rehman (2011) encounter that actual purchase is difference by industries.

\subsection{Attitude}

Attitude toward behaviour refers to the degree to which a person has a favourable or unfavourable evaluation of the behaviour in question (Ajzen, 1991). Basically, the key role of attitude in making certain positive or negative assessment of behaviour and actual purchase has been noted in previous research (Ajzen \& Fishbein, 1980). Characteristically, (Ramayah, Lee, \& Mohamad, 2010) opined that attitude includes observed consequences associated with behaviour. Attitude is the psychological emotion routed through consumers' evaluations and, if positive, behavioural intentions tend to be more positive (Haque, Rahman, \& Haque, 2011).In line with the above positions, a myriad of studies have been done with findings suggesting that attitude influences behaviour directly and it is considered as a better predictor than intention (Hashjin, VakilaRoaia, \& Hemati, 2014). Specifically, a study carried out with a focus on herbal products found that attitude influenced the use of herbal products (Marinac et al., 2007) . In light of the above, the following hypothesis is proposed;

H1: Attitude is positively related to actual purchase.

\subsection{Social Influence}

In the TPB model, a second determinant of behavioural intention is social influence. Social influence is usually related to the trust that a person have on a person's feelings and behaviours (Chow, Chen, Yeow, \& Wong, 2012). Social influence has been examined by researchers (Conner, Kirk, Cade, \& Barrett, 2003; Pawlak et al., 2007) and more specifically in the marketing and consumer behaviour 
(Budiman, 2012; Haque et al., 2011) while the results from the above studies affirm the ability of social influence in explaining behaviour. More characteristically, some studies have also been done with focus on the use of herbal medicine, found that social influence does affected the usage of the product (Gupchup et al., 2006). Based on the above positions on the relationship between social influence and actual behaviour, the following hypothesis is proposed:

$\mathrm{H} 2$ : Social Influence is positively related to the actual purchase

\subsection{Perceived Benefit}

Previous studies encounter that customer who uses herbal product as alternative in order to maintain good health and also trust the benefit of the product (Amin et al., 2011; Vos \& Brennan, 2010). Furthermore pass studies revealed that customer who are confident with the product supremacy are more possible to use it (O'Connor \& White, 2009; Goldstein, Lee, Ballard-Barbash, \& Brown, 2008). Meanwhile other studies found that herbal product provided advantage to them. Based on these views, the following hypothesis is hereby proposed:

H3: Perceived benefit will moderate the relationship between attitude and actual purchase, such that this relationship will be stronger when perceived benefit is high, than when it is low.

Based on the TPB, this study explores the relationship between attitudes, social influence, and actual purchase of herbal products. We further explore how perceived benefit moderate the relationship between attitude and actual purchase. This model is represented visually in Figure 1.

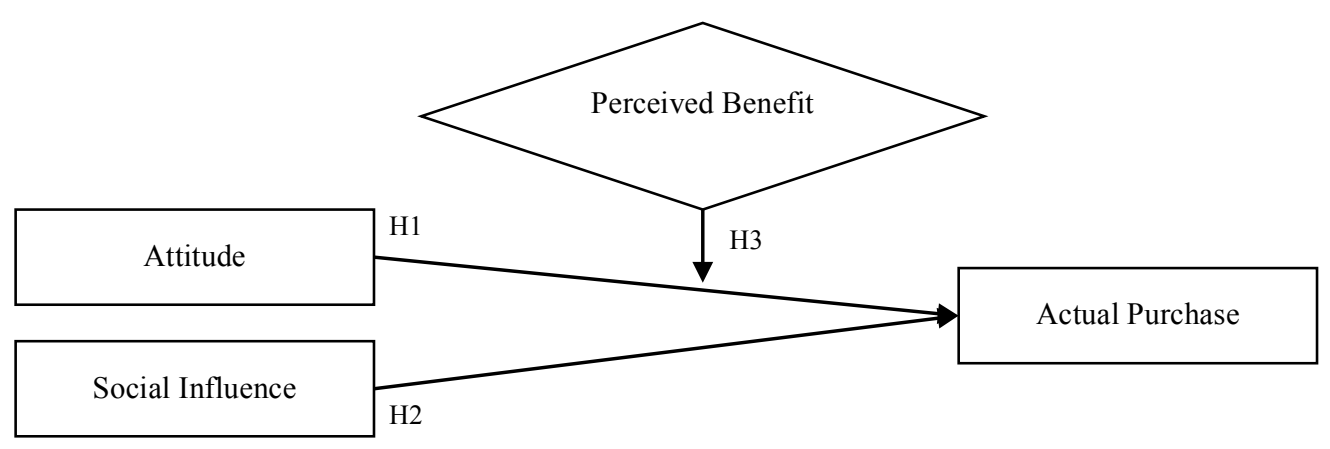

Fig. 1. Research Model

\section{Methodology}

\subsection{Population}

The population for this study consists of the 573 users of herbal products, aged 18 years and above. Concurrently quota sampling and mall intercept were used to determine the sampling technique and data collection methods. According Lohr (1999) quota sampling is found to be suitable for marketing research. Meanwhile the mall intercept selection is to maximize the character of the respondent in term 
eISSN: 2357-1330

Selection and peer-review under responsibility of the Organizing Committee

of geographical and socio-economic. A total of 30 supermarkets were randomly selected from six states in Malaysia (Penang, Kuala Lumpur, Johor, Kelantan, Terengganu and Pahang). The data collection was done during the week from 11.00 am to $9.00 \mathrm{pm}$. As result a total of $82 \%$ questionnaire return.

\section{Analysis and Results}

This study uses Smart PLSM3 (Ringle, Wende, \& Becker, 2015) software in order to analyse the data with the use of bootstrapping technique to decide on the significant level. As per recommendation by Hair, Hult, Ringle, \& Sarstedt (2014) this study used two-stage approach in order to determine the validity and reliability of the measure and the second process followed by examining the structural model.

\subsection{Measurement Model}

The convergent validity for this study were estimate through factor loading, composite reliability (CR) and average variance extracted (AVE) (Hair et al., 2014). The result showed that composite reliability value exceeded the recommended value of 0.7 , while average value extracted exceed the recommended value 0.5. Meanwhile the discriminant validity done by measuring other construct square root of the AVEs (diagonal values) with the corresponding correlation coefficients (off-diagonal values) and demonstrate suitable discriminant validity (Fornell \& Larcker, 1981). Overall the measurement model exhibits acceptable convergent validity and discriminant validity.

\subsection{Structural Model}

Following the assessment of the measurement model, the hypothesized relationships in the structural model were tested. Results of the analysis indicated that attitude $(\beta: 0.189, \mathrm{t}: 3.096, \mathrm{p}<0.01)$, social influence $(\beta: 0.188, \mathrm{t}: 3.806, \mathrm{p}<0.01)$ discovered to exert a positive impact on actual purchase explaining $59 \%$ of variance found in actual purchase. Lastly perceived benefit ( $\beta:-0.061, \mathrm{t}: 2.043$, $\mathrm{p}<0.050)$ moderate the relationship between attitude and actual purchase. In sum, the results provide sufficient evidence to support all the hypotheses $(\mathrm{H} 1, \mathrm{H} 2, \mathrm{H} 3)$ tested in this study.

\section{Conclusion and Discussion}

This study on the factor that influence the purchase of herbal products has contribute to the understanding and useful to the marketing manager as a fundamental factor that influence the actual purchase of herbal product and benefit when drawing up their marketing strategy. The result suggest that attitude toward herbal product is capable of influencing actual purchase significantly and positively. The finding in this study was consistent with previous study (Gupchup et al., 2006). Meanwhile analysis showed that the relationships between social influence and actual purchase were significantly positive, this finding was also supported by several previous studies that showed that social influence plays a very important role in actual purchase (Ahmed Al-Qasa, 2013). Furthermore perceived benefit as moderator on the relation between attitude and actual purchase were significant and it showed that the relationship is more positive for buyers who have a high perceive benefit 
compared to buyers with low perceived benefits. The findings from this study indicate that the attitude and the actual purchase is more compelling for buyers who have a high perception of benefit compared to buyers with low perceived benefits. Thus, these findings support the formulated hypothesis.

\section{Limitations and Suggestions for future research}

The study focuses on a specific product when examining the relationship between attitude, social influence and actual purchase of herbal product. This would suggest that findings could not be easily generalizable to all herbal products. Furthermore generalizability of the findings of this study seems limited as it is both product and context specific. Perhaps future research should also look into other product such as phytomedicines, nutraceutical, functional food, cosmetic and personal care products.

\section{References}

Ab Karim, M. ., Nasouddin, S. ., Othman, M., Mohd Adzahan, N., \& Hussin, S. . (2011). Consumers ' knowledge and perception towards Melicope ptelefolia ( Daun Tenggek Burung ): A preliminary qualitative study. International Food Research Journal, 18(4), 1481-1488.

Ahmed Al-Qasa, K. M. (2013). Factors Determining The Purchase Intention Of Bank Services in The Republic of Yamen. (Unpublished PhD thesis) Universiti Utara Malaysia.

Ajzen, I. (1985). From Intention to Actions: A Theory of Planned Behaviour. In Springer Series ini Sosial Psychology (pp. 11-39). Verlag Berlin Heidelberg: Springer Berlin Heidelberg.

Ajzen, I. (1991). The Theory of Planned Behavior. Organizational Behavior and Human Decision Processes, 50(2), 179-211.

Ajzen, I., \& Fishbein, M. (1980). Understanding attituted and predicting social behavior. Englewood Cliffs,NJ: Prentice Hall.

Al-Ekam, J. M. E. (2013). Actual Purchase Behavior of Local Brand Antecedents in Yemen: The Mediating Effect of Purchase Intention. (Unpublished $\mathrm{PhD}$ thesis) Universiti Utara Malaysia.

Amin, L., Ahmad, J., Md. Jahi, J., Md. Nor, A. R., Osman, M., \& Mahadi, N. M. (2011). Factor Influencing Malaysian Public Attitude to Argo-Biotechnology. Public Understanding of Science, 20(5), 674-689.

Aziz, Z., \& Tey, N. P. (2009). Herbal medicines: prevalence and predictors of use among Malaysian adults. Complementary Therapies in Medicine, 17, 44-50.

Chow, M. M., Chen, L. H., Yeow, J.-A., \& Wong, P. W. (2012). Conceptual Paper : Factors Affecting the Demand of Smartphone among Young Adult. Social Science Economics \& Art, 2(2), 44-49.

Conner, M., Kirk, S. F., Cade, J. E., \& Barrett, J. H. (2003). Dietary Supplement Use in Women: Current Status and Future Directions Environmental Influences : Factors Influencing a Woman' $\mathrm{s}$ Decision to Use Dietary Supplements 1, 2. The Journal of Nutrition, (4), 1978-1982.

Euromonitor International. (2016). Herbal/Traditional Products-Market Size. Retrieved from http://www.euromonitor.com/herbal-traditional-products-in-Malaysia

Fornell, C., \& Larcker, D. F. (1981). Evaluating Structural Equation Models with Unobservable Variable and Measuarement Error. Journal of Marketing Research, 18(1), 39-50.

Goldstein, M. S., Lee, J. H., Ballard-Barbash, R., \& Brown, E. R. (2008). The Use and Perceived Benefit of Complementary and Alternative Medicine Among Californians with Cancer. PsychoOncology, 17, 19-25.

Gupchup, G. V., Abhyankar, U. L., Worley, M. M., Raisch, D. W., Marfatia, A. A., \& Namdar, R. (2006). Relationships between Hispanic ethnicity and attitudes and beliefs toward herbal medicine use among older adults. Research in Social \& Administrative Pharmacy, 2, 266-279.

Hair, J. F. J., Hult, G. T. M., Ringle, C. M., \& Sarstedt, M. (2014). A Primer On Partial Least Squares Structure Equation Modeling (PLS-SEM). Sage Publications Inc.

Haque, A., Rahman, S., \& Haque, M. (2011). Religiosity , Ethnocentrism and Corporate Image Towards the Perception of Young Muslim Consumers : Structural Equation Modeling Approach. European Journal of Social Sciences, 23(1), 98-108.

Hashjin, S. T., VakilaRoaia, Y., \& Hemati, M. (2014). The Study of Factors Influencing the Accepting 
of Internet Banking (Case Study : Bank Sepahin Alborz Province ). Arabian Journal of Business and Management Review (OMAN Chapter), 3(7), 85-98.

Kanodia, A. K., Legedza, A. T. R., Davis, R. B., Eisenberg, D. M., \& Phillips, R. S. (2010). Perceived Benefit of Complementary and Alternative Medicine (CAM) for Back Pain: A National Survey. Journal of the American Board of Family Medicine: JABFM, 23(May-June), 354-362.

Kim, H. Y., \& Chung, J.-E. (2011). Consumer Purchase Intention For Organic Personal Care Products. Journal of Consumer Marketing, 28(1), 40-47.

Lohr, S. L. (1999). Sampling: Design and Analysis, 265-272.

Marinac, J. S., Buchinger, C. L., Godfrey, L. A., Wooten, J. M., Sun, C., \& Willsie, S. K. (2007). Herbal Products and Dietary Supplements: A Survey of Use, Attitudes, and Knowledge Among Older Adults. World Health, 107(1), 13-23.

O'Connor, E. L., \& White, K. M. (2009). Intentions and Willingness To Use Complementary and Alternative Medicines: What Potential Patients Believe About CAMs. Complementary Therapies in Clinical Practice, 15, 136-140.

P.Pomsanam, K.Napompech, \& S.Suwanmaneepong. (2014). An Exploratory Study on the Organic Food Purchase Intention Among Thai-Cambodian Cross-Border Consumers. Asian Journal of Applied Sciences, 7(5), 294-305.

Paul, J., \& Rana, J. (2012). Consumer Behavior and Purchase Intention For Organic Food. Journal of Consumer Marketing, 29(6), 412-422.

Pawlak, R., Brown, Æ. D., Kay, Æ. M., Connell, C., Yadrick, Æ. K., \& Blackwell, A. (2008). Theory of Planned Behavior and Multivitamin Supplement Use in Caucasian College Females. Journal Primary Prevention, 29(1), 57-71.

Ramayah, T., Lee, J. W. C., \& Mohamad, O. (2010). Green product purchase intention: Some insights from a developing country. Resources, Conservation and Recycling, 54(12), 1419-1427.

Rezai, G., Zahran, M. Z. M., \& Mohamed, Z. (2013). Factors Influencing Malaysian Consumers Online Purchase of Herbal Products. Pertanika Jounal Social Science \& Human, 21(S), 109-122.

Ringle, C. M., Wende, S., \& Becker, J.-M. (2015). SmartPLS. Boenningstedt,Germany: SmartPLS $\mathrm{GmbH}$. Retrieved from www.smartpls.com

Saokaew, S., Suwankesawong, W., Permsuwan, U., \& Chaiyakunapruk, N. (2011). Safety of Herbal Products in Thailand An Analysis of Report in the Thai Health Product Vigilance Center Database from 2000 to 2008, 34(4), 339-351.

Shafiq, R., Raza, I., \& Zia-ur-rehman, M. (2011). Analysis of the factors Affecting Customers' Purchase Intention: The Mediating Role of Perceived Value. African Journal of Business Management, 5(26), 10577-10585.

Vos, L., \& Brennan, R. (2010). Complementary and Alternative Medicine: Shaping a Marketing Research Agenda. Marketing Intelligence \& Planning, 28(3), 349-364.

Zia-ur-Rehman, \& Dost, M. K. (2013). Conceptualizing Green Purchase Intention in Emerging Markets: An Empirical Analysis on Pakistan. In The 2013 WEI International Academic Conference Proceedings (pp. 99-120). 